\title{
Effect of SiC Nanorods on Mechanical and Thermal Properties of SiC Composites Fabricated by Chemical Vapor Infiltration
}

\author{
Ho Wook Lee*,**, Daejong Kim*, Hyeon-Geun Lee*, Weon-Ju Kim*, \\ Soon Gil Yoon**, and Ji Yeon Park ${ }^{*} *, \dagger$ \\ *Advanced Materials Research Division, Korea Atomic Energy Research Institute, Daejeon 34057, Korea \\ **Department of Material Science and Engineering, Chungnam National University, Daejeon 34134, Korea
}

(Received May 22, 2019; Revised August 6, 2019; Accepted August 7, 2019)

\begin{abstract}
To reduce residual pores of composites and obtain a dense matrix, $\mathrm{SiC}_{\mathrm{f}} / \mathrm{SiC}$ composites were fabricated by chemical vapor deposition (CVI) using SiC nanorods. SiC nanorods were uniformly grown in the thickness direction of the composite preform when the reaction pressure was maintained at 50 torr or 100 torr at $1,100^{\circ} \mathrm{C}$. When $\mathrm{SiC}$ nanorods were grown, the densities of the composites were $2.57 \sim 2.65 \mathrm{~g} / \mathrm{cm}^{3}$, higher than that of the composite density of $2.47 \mathrm{~g} / \mathrm{cm}^{3}$ for non-growing of SiC nanorods under the same conditions; grown nanorods had uniform microstructure with reduced large pores between bundles. The flexural strength, fracture toughness and thermal conductivity (room temperature) of the SiC nanorod grown composites were $412 \sim 432 \mathrm{MPa}$, $13.79 \sim 14.94 \mathrm{MPa} \mathrm{m}^{1 / 2}$ and $11.51 \sim 11.89 \mathrm{~W} / \mathrm{m} \cdot \mathrm{K}$, which were increases of $30 \%, 25 \%$, and $25 \%$ compared to the untreated composite, respectively.
\end{abstract}

Key words : $\mathrm{SiC}_{f} / \mathrm{SiC}, \mathrm{SiC}$ nanorod, Densification, Mechanical property, Thermal property

\section{Introduction}

$\mathrm{S}$ iC-based ceramics are considered as materials for high temperature parts of gas turbines or core parts of reactor cores that require high temperature structural properties due to their excellent mechanical and thermal properties, chemical stability at high temperature, and good neutron radiation resistance. ${ }^{1-4)}$ Monolithic $\mathrm{SiC}$, however, has brittle fracture behavior, limiting its use as a construction material. To overcome this shortcoming, Continuous Fiber Reinforced Ceramic Composites (CFCCs) have been developed..$^{5-6)}$ $\mathrm{SiC}$ fiber-reinforced $\mathrm{SiC}$-matrix $\left(\mathrm{SiC}_{\mathrm{f}} / \mathrm{SiC}\right)$ composites are mainly fabricated using the Chemical Vapor Infiltration (CVI) method, ${ }^{7-8)}$ the Si melt infiltration method, ${ }^{9}$ the Polymer Impregnation and Pyrolysis (PIP) method, ${ }^{10)}$ hot pressing method, ${ }^{11-13)}$ and hybrid processes that combine two of these methods. ${ }^{14-15)}$

$\mathrm{SiC}_{\mathrm{f}} / \mathrm{SiC}$ composites contain $\mathrm{SiC}$ fibers as reinforcing materials and $\mathrm{SiC}$ as a matrix phase, and both materials are known to exhibit excellent heat and radiation resistance when they contain $\beta$-SiC with an excellent stoichiometric ratio, a high-crystallinity phase, and small amounts of impurities. Among the various composite fabrication methods, the CVI method is advantageous in that it is possible to

Corresponding author : Ji Yeon Park

E-mail : jypark@kaeri.re.kr

Tel : +82-42-868-2311 Fax : +82-42-868-8549

ORCID

https://orcid.org/0000-0002-4065-9470 fabricate $\mathrm{SiC}_{\mathrm{f}} / \mathrm{SiC}$ composites with a high-crystallinity matrix phase and excellent stoichiometric ratio. The CVI process performs at low temperatures and pressures, thus minimizing any damage that might occur to the fibers used. Accordingly, CVI-SiC $/ \mathrm{SiC}$ composites have excellent heat resistance, radiation resistance, and mechanical properties. However, these composites contain residual large pores in them, which cause to degrade their mechanical and thermal properties. ${ }^{7)}$ To address this, new processes that use SiC whiskers or nanowires have been developed. ${ }^{16-18)}$

In this study, $\mathrm{SiC}$ nanorods grew on $\mathrm{SiC}$ fibers before filling the matrix to improve the residual pore problems in the CVI-SiC $/$ / $\mathrm{SiC}$ composites. An attempt to change the size and structure of large pores by growing $\mathrm{SiC}$ nanorods could be resulted in improving the behaviors of matrix filling. To this end, SiC nanorods were grown with reaction pressure and temperature to establish optimum growth conditions and to evaluate the effects on mechanical and thermal properties. In addition, a pyrolytic carbon (PyC) layer was further deposited on the SiC nanorods as a means of reinforcing the matrix phase, and the reinforcing effect of these coated $\mathrm{SiC}$ nanorods on the matrix phase was analyzed.

\section{Experimental Procedure}

In this study, a plain-woven $\mathrm{SiC}$ fabric of Tyranno-SA3 (PSA-S17I16PX, Ube Ltd., Japan) was used, and preforms were made by stacking 15 sheets of disc-shaped $\mathrm{SiC}$ fabric with a diameter of 2 inches in $0^{\circ}$ and $90^{\circ}$ directions. At the interface of the fiber and matrix, pyrolytic carbon was 
Table 1. Growth Conditions of SiC Nanorods

\begin{tabular}{cccc}
\hline $\begin{array}{r}\text { Growth } \\
\text { Conditions }\end{array}$ & $\begin{array}{c}\text { Temperature } \\
\left({ }^{\circ} \mathrm{C}\right)\end{array}$ & $\begin{array}{c}\text { Pressure } \\
\text { (torr) }\end{array}$ & $\begin{array}{c}\text { Time } \\
(\mathrm{h})\end{array}$ \\
\hline WG 001 & 1100 & 10 & 5 \\
WG 002 & 1100 & 50 & 5 \\
WG 003 & 1100 & 100 & 5 \\
WG 004 & 1000 & 50 & 5 \\
WG 005 & 1200 & 50 & 5 \\
WG 006 & 1100 & 25 & 5 \\
\hline
\end{tabular}

deposited at $1,100^{\circ} \mathrm{C}$ and 90 torr in a chemical gas reactor using $\mathrm{CH}_{4}$ as the raw material gas. The thickness of the PyC layer was set to $150-200 \mathrm{~nm}$, within which its mechanical properties are known to be excellent. ${ }^{19)}$

$\mathrm{SiC}$ nanorods must be uniformly widely distributed throughout the fiber and grow thin and long to aid in subsequent chemical vapor infiltration processes. The present study attempted to determine the optimal conditions for the $\mathrm{SiC}$ nanorods to grow, with the reaction pressure and temperature set as process variables. Test conditions for the $\mathrm{SiC}$ nanorod growth experiment, along with the specimen names used, are summarized in Table 1 . In addition, after depositing a pyrolytic carbon layer on the SiC nanorod, an experiment was conducted to investigate the effect of enhancing fracture toughness by the interface layers between nanorods and matrix. $\mathrm{CH}_{3} \mathrm{SiCl}_{3}$ (MTS: Methyltrichlorosilane, SIGMA- ALDRICH) was used as a raw material for the infiltration process because it is an organometallic compound that can be easily used to stoichiometrically form the deposition layer, given that the content ratio of $\mathrm{Si}$ to $\mathrm{C}$ is 1:1. The deposition process was performed at $1,000^{\circ} \mathrm{C}$ for $50 \mathrm{~h}$.

A scanning electron microscope (Sirion, Fei, USA) was used to observe the microstructure of the fabricated composites at each stage so that the matrix-phase filling behavior could be examined, especially with regards to the level of $\mathrm{SiC}$ nanorod growth, the degree of densification of the matrix phase, and damage behavior of the fibers and nanorods at the fracture surfaces. The uniformity of nanorod growth was assessed based on the diameter of the $\mathrm{SiC}$ nanorods at the inlet and outlet regions for reaction gases, measured at more than 20 spots and averaged using microstructure images and an image analyzer. After the reaction, a phase analysis of the $\mathrm{SiC}$ nanorods and the matrix phase was conducted using an X-ray diffractometer (X-Ray Diffraction: XRD, SmartLab, Rigaku, Japan) with a scan range of $20^{\circ}-80^{\circ}$, a scan speed of $5^{\circ} / \mathrm{min}$, a step size of $0.02^{\circ}$, and a power of $45 \mathrm{kV} 200 \mathrm{~mA}$.

Also, to assess the effect of the $\mathrm{SiC}$ nanorods on the properties of the $\mathrm{SiC}_{\mathrm{f}} / \mathrm{SiC}$ composites, the flexural strength, fracture toughness, specific heat, and thermal diffusivity were measured. To this end, two types of specimens with different $\mathrm{SiC}$ nanorod growth conditions, as well as specimens in which SiC nanorods were not formed, were prepared. These disk-shaped specimens, with a diameter of $6 \mathrm{~mm}$ and a thickness of $1 \mathrm{~mm}$, were used to measure thermal diffusivity with a laser flash analyzer (LFA 467, NETZSCH, Germany). Also, a differential scanning calorimeter (DSC204 F1 Phoenix, NETZSCH, Germany) was used to measure the specific heat in the range from room temperature to $300^{\circ} \mathrm{C}$. The thermal conductivity was obtained using Eq. (1) below.

$$
\mathrm{K}=\alpha \times \rho \times \mathrm{C}_{\mathrm{p}}
$$

Here, $\mathrm{K}=$ Thermal conductivity

$\alpha=$ Thermal diffusivity coefficient

$\rho=$ Density

$\mathrm{C}_{\mathrm{p}}=$ Specific heat

A universal testing machine (UTS, Instron 4465, USA) was used to measure the mechanical properties; the threepoint flexural strength was measured, and the fracture toughness was determined using a single edge V-notch beam and Eq. (2) and (3). The width, length, and breadth of the specimen were $30 \mathrm{~mm} \times 3 \mathrm{~mm} \times 3 \mathrm{~mm}$ with a tolerance of $\pm 0.1 \mathrm{~mm}$.

$$
\begin{aligned}
\mathrm{K}_{\mathrm{IC}}= & 3 \mathrm{P}\left(\mathrm{S}-\mathrm{S}_{0}\right) \alpha^{1 / 2} \mathrm{Y} / \mathrm{BW}^{1.5} * 2(1-\alpha)^{1.5} \\
\mathrm{Y}= & 1.9887-1.326(\mathrm{a} / \mathrm{W})-\left(3.49-0.68(\mathrm{a} / \mathrm{w})+1.35(\mathrm{a} / \mathrm{W})^{2}\right) \\
& \alpha(1-\alpha)(1+\alpha)^{-2}
\end{aligned}
$$

Where, $\mathrm{P}=\max$ load

$$
\begin{aligned}
& \mathrm{S}=\text { Outer span } \\
& \mathrm{S}_{0}=\text { Inner span } \\
& \mathrm{A}=\text { Crack length } \\
& \alpha=\mathrm{a} / \mathrm{W} \\
& \mathrm{W}=\text { Width of the specimen } \\
& \mathrm{B}=\text { Thickness of the specimen }
\end{aligned}
$$

\section{Results and Discussion}

\subsection{Growth Behavior of SiC Nanorods}

$\mathrm{SiC}$ nanorods were grown during five hours of reaction

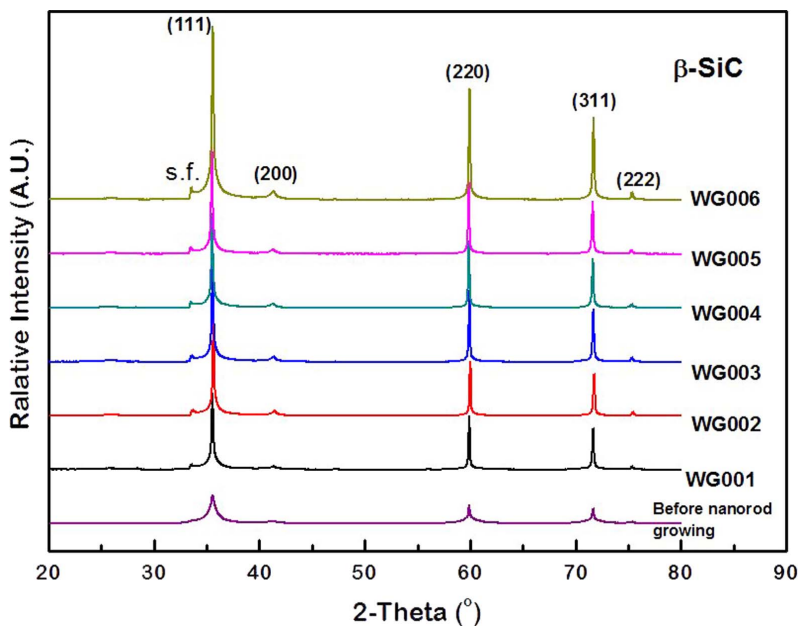

Fig. 1. XRD patterns of SiC preforms containing $\mathrm{SiC}$ nanorods grown under different conditions. 

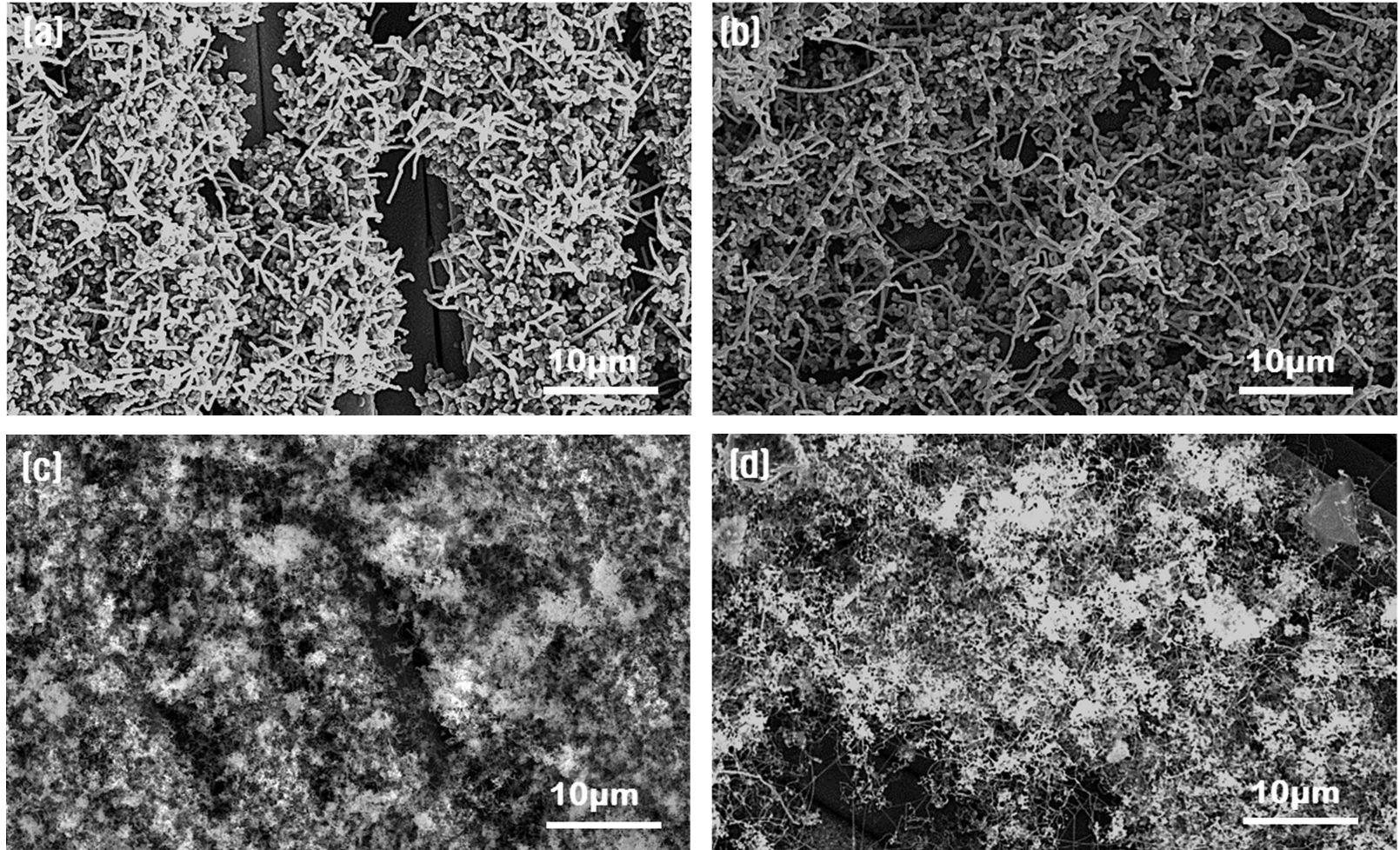

Fig. 2. Microstructures of $\mathrm{SiC}$ preforms containing $\mathrm{SiC}$ nanorods grown at $1,100^{\circ} \mathrm{C}$ under different pressures: (a) 10 torr (WG 001) (b) 25 torr (WG 006) (c) 50 torr (WG 002) (d) 100 torr (WG 003).

with the reaction pressure and temperature set as process variables. The phase analysis results of the $\mathrm{SiC}$ nanorods are presented in Fig. 1. As shown in these XRD analysis results, at reaction conditions of $1,000-1,200^{\circ} \mathrm{C}$ and $10-100$ torr, only $\beta$-phase $\mathrm{SiC}$ was formed and grown regardless of the reaction pressure and temperature. Also, a low-intensity peak which was not observed in the $\mathrm{SiC}$ preform specimen in which $\mathrm{SiC}$ nanorods had not been formed, was found to exist at a diffraction angle lower than that of the (111) peak (labeled as s.f. in Fig. 1). This peak is associated with stacking faults and frequently observed in materials with a large aspect ratio, such as $\mathrm{SiC}$ nanorods, nanowires, and whiskers. ${ }^{2021)}$ This type of peak is known to occur by the $\mathrm{SiC}$ nanorods grow in the [111] direction because of the low surface energy of the $\{111\}$ plane, and easy insert of the stacking fault in the [111] plane perpendicular to the growth direction. Stacking fault formation of nanowires or whiskers by CVD has been reported in previous studies and has also been reported in whisker growth by solid-gas reactions such as carbothermal reactions. ${ }^{19,22-24)}$ As can be seen in the microstructure of Fig. 2, the SiC nanorods grow evenly in the radial direction on the surface of the $\mathrm{SiC}$ fiber. The growth behavior of the $\mathrm{SiC}$ nanorods was investigated with respect to the varying reaction pressure at the fixed reaction temperature, and with respect to the varying reaction temperature at the fixed reaction pressure, respectively. The quantitative criteria for determining the adequacy of $\mathrm{SiC}$ nanorod growth are uncertain. The growth of $\mathrm{SiC}$ nanorods in the preform can increase the $\mathrm{SiC}$ deposition efficiency in a matrix fill process. However, rapid deposition may cause clogging effects, making it difficult for the reaction gas to penetrate into the preform, thereby leaving the matrix filling process with large pores. In addition, it is difficult to obtain a uniform microstructure in the thickness direction of the specimen during the $\mathrm{SiC}$ nanorod growth and matrixphase filling process when the reaction conditions are different around the specimen at the reactant feed inlet and outlet portions. In the present study, the Forced-CVI process was applied, which improves the efficiency of matrix-phase filling, using the pressure difference between the inlet and outlet of the reaction gases. Given the characteristics of the process, the two regions cannot have uniform reaction conditions. Accordingly, the formed $\mathrm{SiC}$ nanorods varied in characteristics, and an attempt was made to find the optimal reaction conditions to minimize such non-uniformity.

To this end, the difference in diameters of SiC nanorods grown in the inlet and outlet regions of the reactor was analyzed using an image analyzer to compare the uniformity in a relative manner. Fig. 2 is the microstructure of $\mathrm{SiC}$ nanorods grown at $1,100^{\circ} \mathrm{C}$ with the reaction pressure to 10 , 25, 50, and 100 torr, respectively, and Fig. 3 is the comparison of the differences between the average diameters of nanorods grown in inlet and outlet region. At reaction pressures of 10 and 25 torr, the average diameter difference of $\mathrm{SiC}$ nanorods between the inlet and the outlet regions was relatively large as $3311 \mathrm{~nm}$ and $3695 \mathrm{~nm}$, respectively, while, at pressures of 50 and 100 torr, the average diameter difference was small as $94 \mathrm{~nm}$ and $466 \mathrm{~nm}$, respectively. 


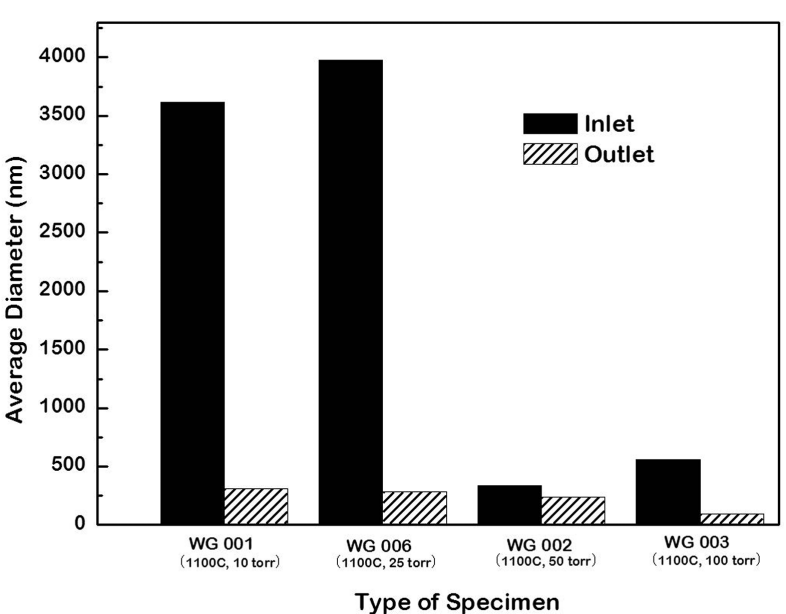

Fig. 3. Comparison of diameters of $\mathrm{SiC}$ nanorods grown at $1,100^{\circ} \mathrm{C}$ with different reaction pressures in gas inlet area and gas outlet area.
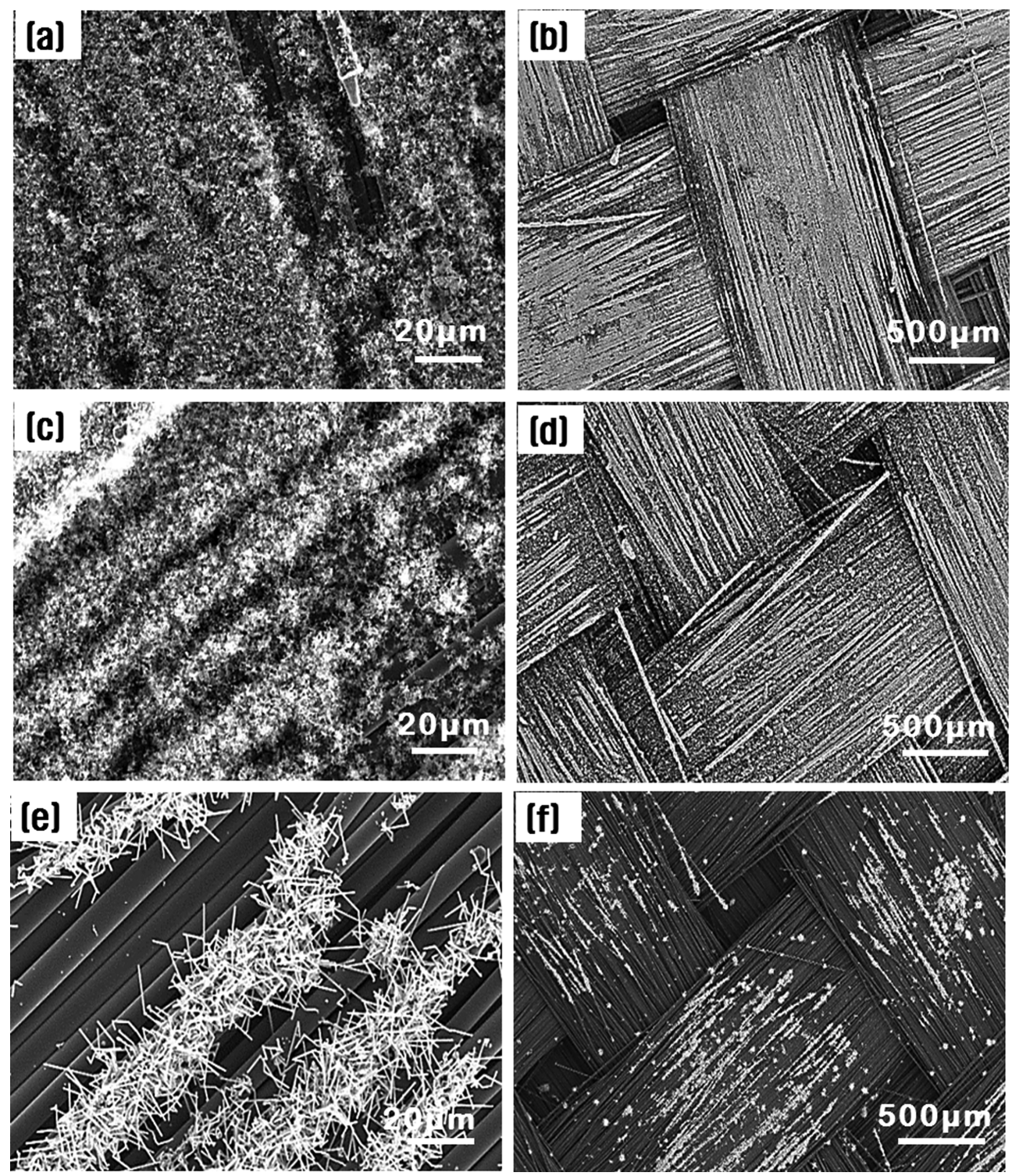

Fig. 4. Microstructures of $\mathrm{SiC}$ preforms containing $\mathrm{SiC}$ nanorods grown at different temperatures: (a), (b) $1000^{\circ} \mathrm{C}$ (WG 004), (c), (d) $1100^{\circ} \mathrm{C}(\mathrm{WG} 002)$, and (e), (f) $1200^{\circ} \mathrm{C}$ (WG 006). 


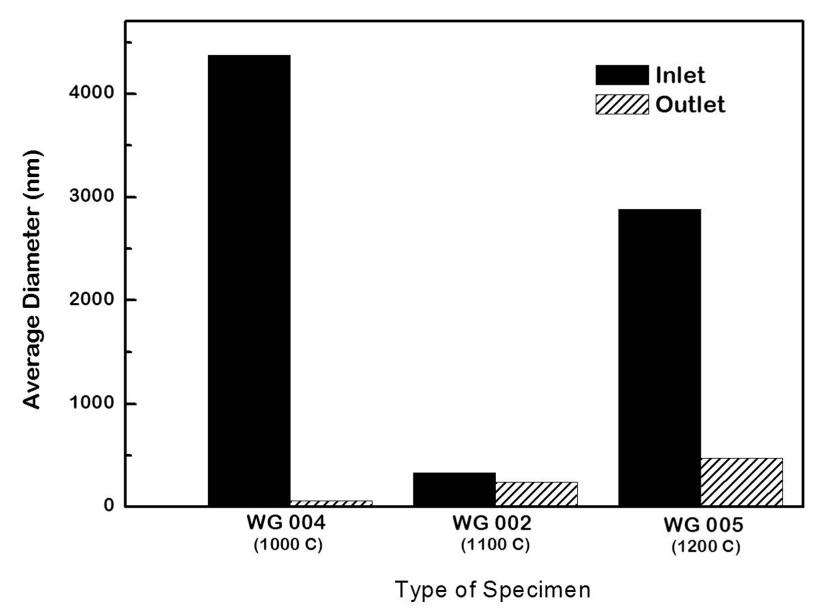

Fig. 5. Comparison of diameters of $\mathrm{SiC}$ nanorods grown at different temperatures at 50 torr in gas inlet area and gas outlet area.

$1,100^{\circ} \mathrm{C}$, (i.e., $94 \mathrm{~nm}$ at $1,100^{\circ} \mathrm{C} ; 4312 \mathrm{~nm}$ at $1,000^{\circ} \mathrm{C} ; 2404$ $\mathrm{nm}$ at $\left.1,200^{\circ} \mathrm{C}\right)$. As a result, the optimal growth conditions for $\mathrm{SiC}$ nanorods were determined, as follows: a reaction temperature of $1,100^{\circ} \mathrm{C}$ with reaction pressures of 50 and 100 torr.

\subsection{SiC Matrix Filling and Property Evaluations}

The matrix filling process was performed at $1,000^{\circ} \mathrm{C}$ for 50 $\mathrm{h}$ in both the preform specimens without $\mathrm{SiC}$ nanorods formed, and the specimens in which $\mathrm{SiC}$ nanorods were formed at $1,100^{\circ} \mathrm{C}$ and 50 torr (or 100 torr). For some of the preform specimens that contained $\mathrm{SiC}$ nanorods, the nanorods were additionally coated with $\mathrm{PyC}$, and the reinforcing effect of the coating was examined. The density of the final $\mathrm{SiC}_{\mathrm{f}} / \mathrm{SiC}$ composite was $2.47 \mathrm{~g} / \mathrm{cm}^{3}$ without growing nanorods, and $2.65 \mathrm{~g} / \mathrm{cm}^{3}$ and $2.57 \mathrm{~g} / \mathrm{cm}^{3}$ with growing nanorods and PyC-coated nanorods, respectively. Fig. 6 shows the microstructure of the vertical cross-section of these composites. Fig. 6(a) indicates that the composite specimens without any nanorods ended up with large pores between bundles that were left unfilled by the matrix phase (indicated with arrow symbols). In the composite specimens with nanorods, however, fewer of these pores existed between bundles, and the matrix phase was uniformly formed with only a small number of tiny pores, as shown in Fig. 6(b) and (c). As similarly observed in previous studies that used SiC whiskers ${ }^{19,25)}$ it was thought that $\mathrm{SiC}$ nanorods divided the large pores contained in the preform into smaller ones, and these newly formed small pores served as new deposition sites for the $\mathrm{SiC}$ matrix phase. This process was considered to have promoted the densification and uniformity of the composites. As shown in Fig. 7, the flexural strength of the composite specimens without any $\mathrm{SiC}$ nanorods was the lowest, at 328.74 MPa. When SiC nanorods were formed, the flexural strength of the composites ranged from 410 to $430 \mathrm{MPa}$, regardless of whether the nanorods had been coated with PyC. As mentioned regarding microstructure in Fig. 6, it
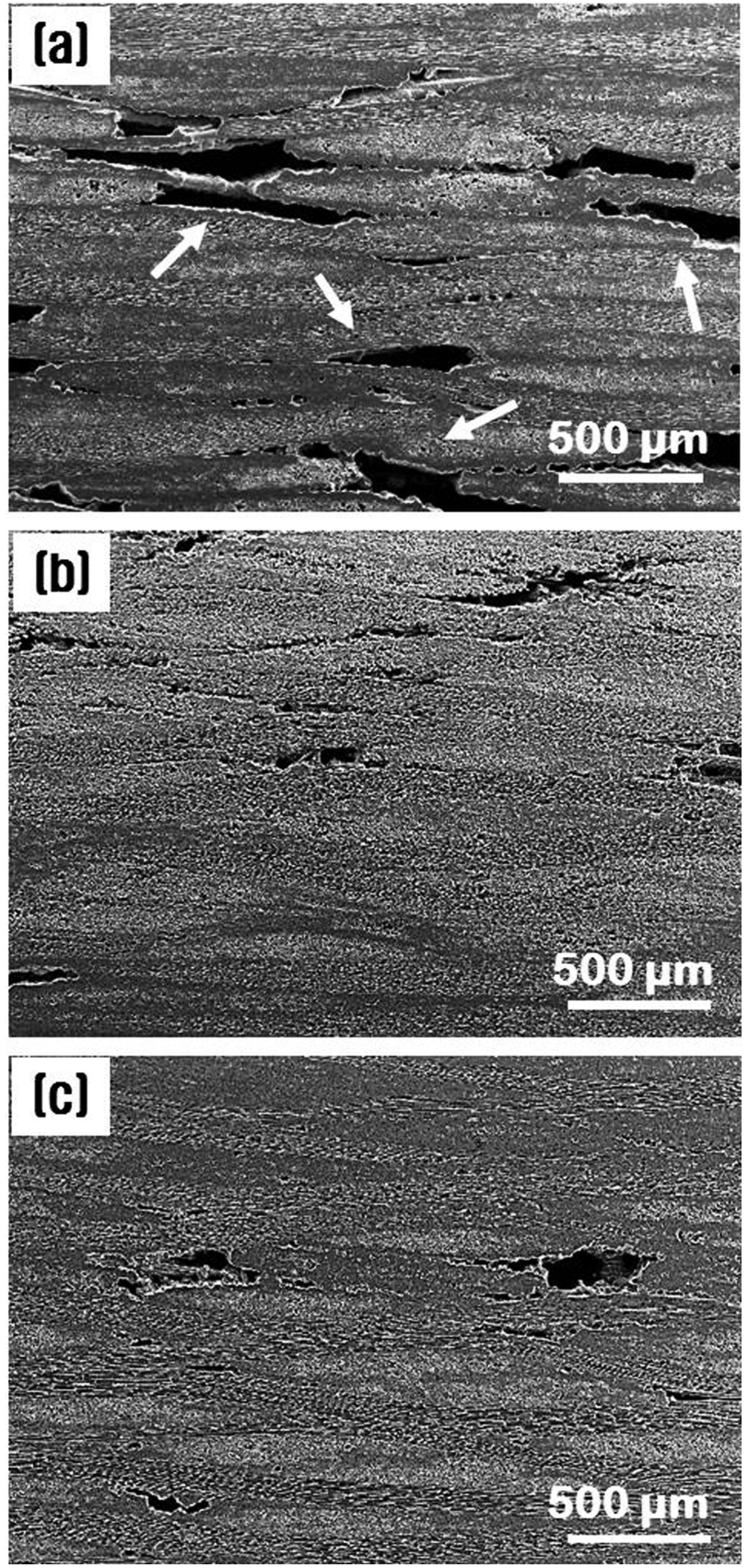

Fig. 6. Cross-sectional microstructures of $\mathrm{SiC}_{\mathrm{f}} / \mathrm{SiC}$ composites prepared at 50 torr and $1,100^{\circ} \mathrm{C}$ for $50 \mathrm{~h}$ : (a) nonnanorods, (b) nanorods and (c) PyC coated nanorods.

was thought that the formation of $\mathrm{SiC}$ nanorods resulted in increased density, fewer large pores, and relatively more uniform structures. These factors are considered to have increased the flexural strength of the composites. As shown in Fig. 8, the fracture toughness was $11.99 \mathrm{MPa} \cdot \mathrm{m}^{1 / 2}$ when without SiC nanorods were formed, and the fracture toughness increased to 14.94 and $13.79 \mathrm{MPa} \cdot \mathrm{m}^{1 / 2}$ when typical nanorods were formed and when $\mathrm{PyC}$-coated nanorods were formed, respectively. However, the additional enhancement of fracture toughness expected by coating $\mathrm{PyC}$ on $\mathrm{SiC}$ 


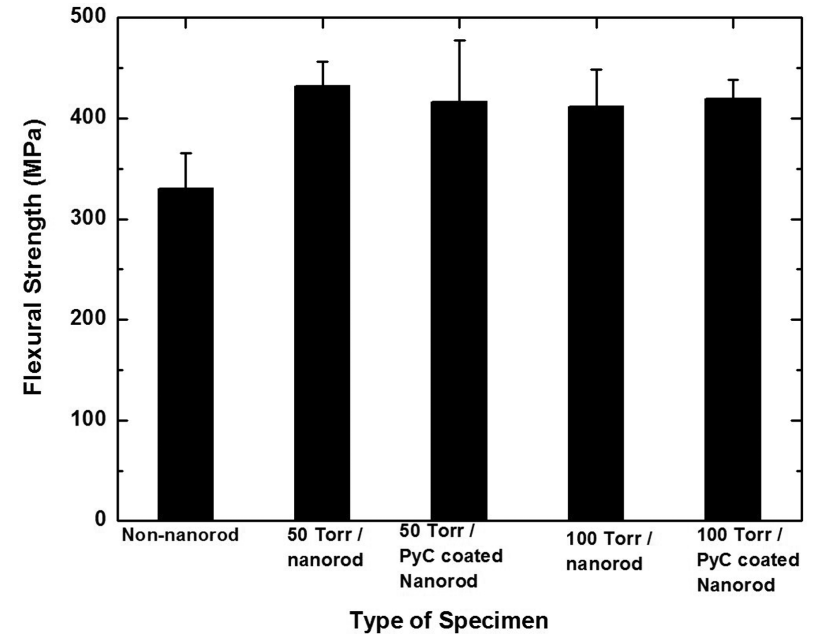

Fig. 7. Flexural strength of other types of $\mathrm{SiC}_{\mathrm{f}} / \mathrm{SiC}$ composites.

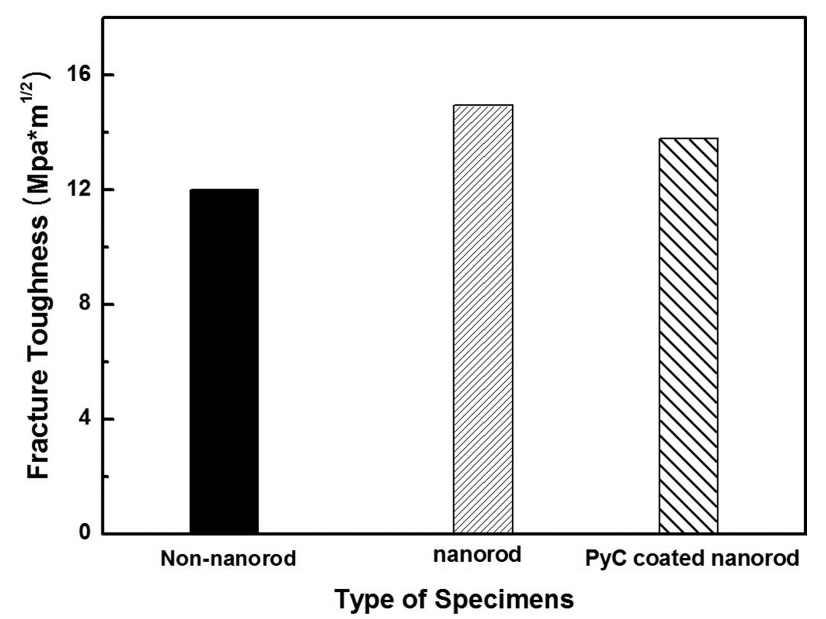

Fig. 8. Fracture toughness of other types of $\mathrm{SiC}_{\mathrm{f}} / \mathrm{SiC}$ Composites.

nanorods was not obviously observed in this study. This is ascribed to the fact that the $\mathrm{PyC}$ coating resulted in a decrease in both the density and uniformity of the microstructure. Fig. 9 presents the microstructure of the fracture surfaces of the composites fabricated using the preforms that contained $\mathrm{PyC}$ coated nanorods. Fig. 9(a) shows images of pulled-out $\mathrm{SiC}$ fibers and the pores formed due to these pulled-out fibers (indicated with arrow symbols), while Fig. 9(b) illustrates how cracks tend to deflect and propagate within the matrix phase (indicated with arrow symbols). However, such phenomenon as the pull out of whiskers on the matrix observed when whiskers were grown instead of nanorods was not observed in this study ${ }^{25)}$ Further microstructural analysis is needed to clarify whether such a phenomenon occurs in practice.

The thermal conductivity measurement was conducted on the composites without any $\mathrm{SiC}$ nanorods formed, the composites where typical $\mathrm{SiC}$ nanorods were formed at 50 torr, and the composites where $\mathrm{PyC}$-coated $\mathrm{SiC}$ nanorods were
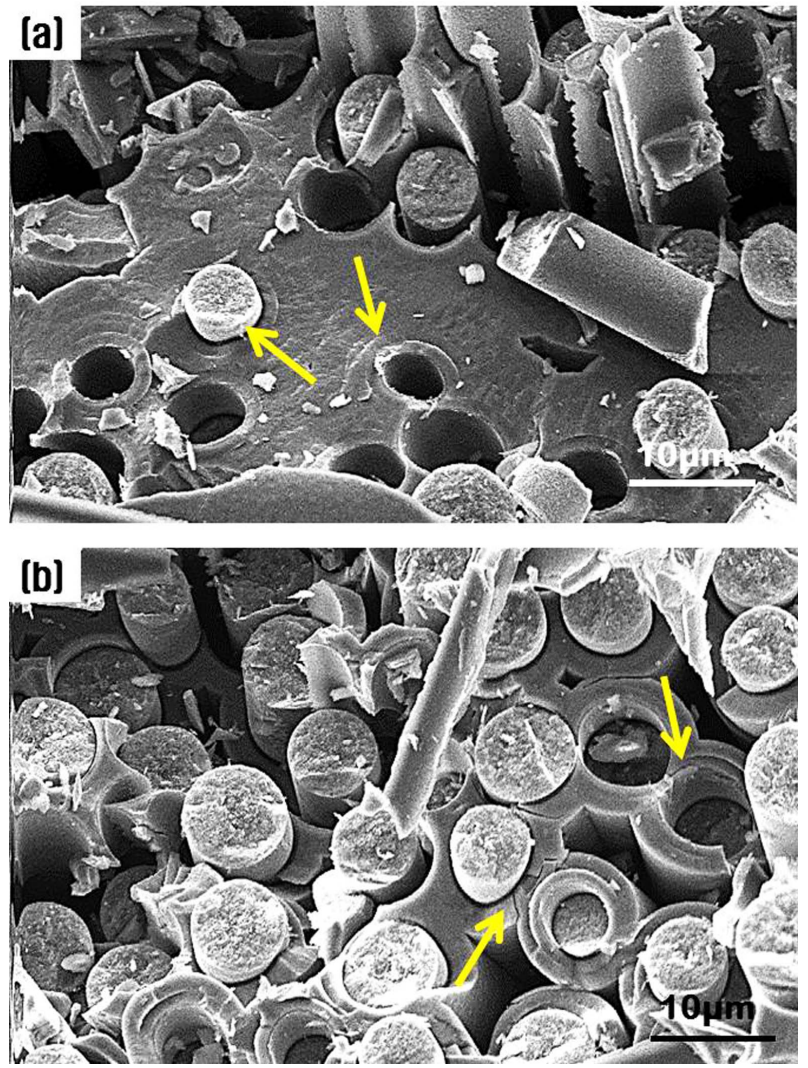

Fig. 9. Fracture surface of $\mathrm{SiC}_{\mathrm{f}} / \mathrm{SiC}$ composites with $\mathrm{PyC}$ coated nanorods showing (a) SiC fiber pull-out and (b) crack deflection (arrow marks).

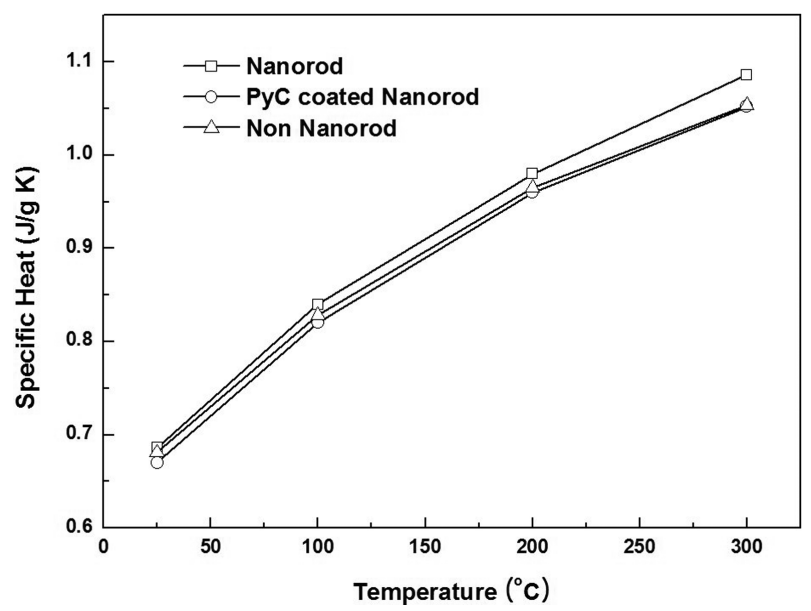

Fig. 10. Specific heat of $\mathrm{SiC}_{\mathrm{f}} / \mathrm{SiC}$ composites measured by DSC.

formed. The specific heat was measured using a differential scanning calorimeter while increasing the temperature to $300^{\circ} \mathrm{C}$, and the measured results are shown in Fig. 10. The thermal conductivity was calculated by inputting the thermal diffusivity (Fig. 11(a)) measured using the laser flash method, the measured specific heat, and the density in Eq. 1, and the results are presented in Fig. 11(b). It was found that the specific heat tended to increase with increasing 

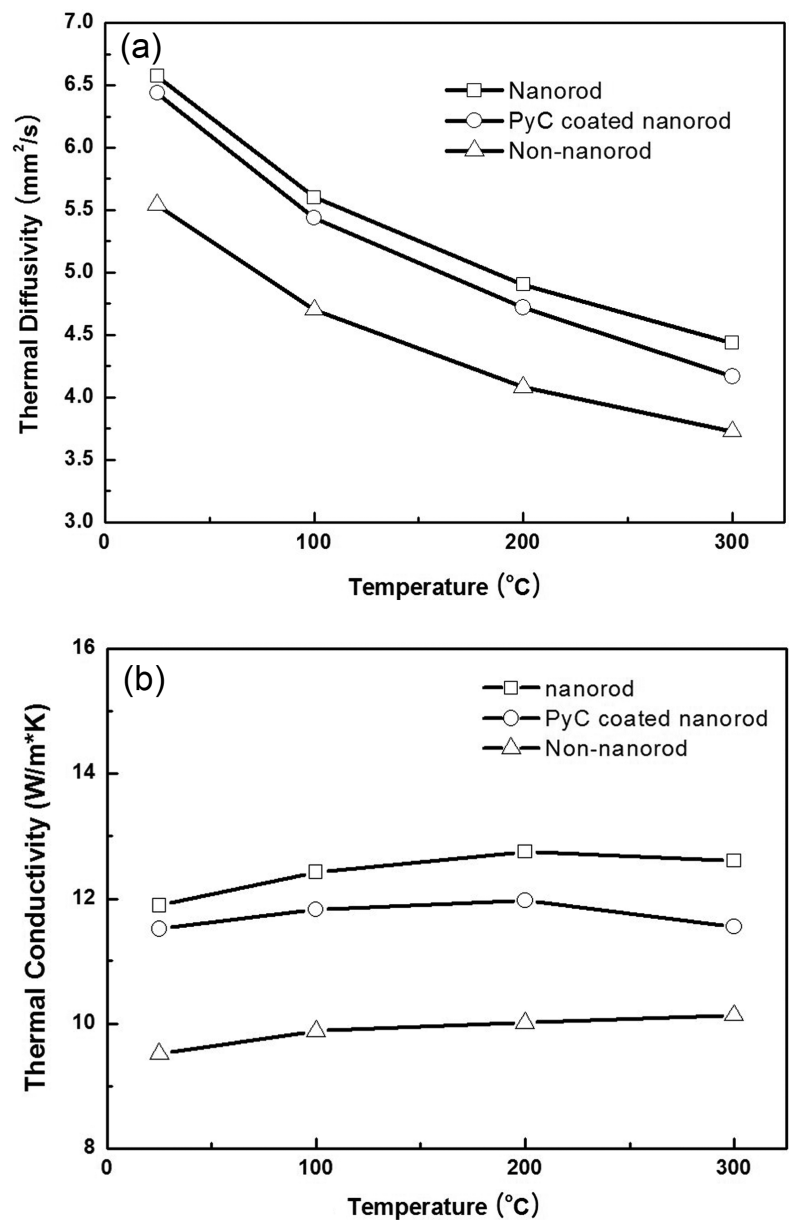

Fig. 11. Thermal diffusivity (a) and conductivity (b) of $\mathrm{SiC}_{\mathrm{f}} /$ $\mathrm{SiC}$ composites.

temperature, but the variation was small; most measurements were similar regardless of the specimen preparation conditions applied. The thermal conductivity was found to range from 9.51 to $12.75 \mathrm{~W} / \mathrm{m} \cdot \mathrm{K}$. This is similar to that reported elsewhere ${ }^{26)}$ for $2 \mathrm{D}-\mathrm{SiC}_{\mathrm{f}} / \mathrm{SiC}$ composites. The figure was the lowest when SiC nanorods were not formed and the highest when typical $\mathrm{SiC}$ nanorods were formed.

Balandin $^{27)}$ reported that the thermal conductivity of $\mathrm{PyC}$ coated layers exhibited anisotropy and thus were $10^{3}$ higher in the in-plane direction than in the cross-plane direction; however, within the temperature range of $0-300^{\circ} \mathrm{C}$, the thermal conductivity was hardly affected by the measurement temperature, when measured in the same in-plane direction. Notably, when measured in the cross-plane direction, the thermal conductivity was found to be $6-8 \mathrm{~W} / \mathrm{m} \cdot \mathrm{K}$ within the temperature range from room temperature to $300^{\circ} \mathrm{C}$, indicating that the figure was not significantly affected by the measurement temperature. The composites fabricated in the present study were two-dimensional structures of $\mathrm{SiC}$ fabric layers stacked on top of each other, and the thermal diffusivity was measured along the cross-plane direction of the PyC layers that were coated on the fibers or nanorods. This was considered to be the reason why the thermal conductivity of the composites was not significantly affected by whether or not the $\mathrm{SiC}$ nanorods contained in them were coated with PyC. The thermal diffusivity of a composite is known to increase with increasing density, ${ }^{28)}$ and a similar trend was observed in the present study, as shown in Fig. 11(a). As shown in Fig. 11(b), the thermal conductivity increased in the order of increasing density, i.e., from the composites without any nanorods formed to the composites where PyC-coated SiC nanorods were formed and further to the composites where typical nanorods were formed. In this regard, the observed improvement in the thermal conductivity was considered to be due to the effects of SiC nanorod formation, which increased the density and microstructural uniformity of the composites.

\section{Conclusions}

$\mathrm{SiC}$ nanorods were found to effectively improve the uniformity of preforms in the thickness direction when formed and grown at a temperature of $1,100^{\circ} \mathrm{C}$ and a pressure of 50 or 100 torr. The formation of $\mathrm{SiC}$ nanorods in $\mathrm{SiC}_{\mathrm{f}} / \mathrm{SiC}$ composites divided large pores into smaller ones, improved the matrix filling effect, and increased the density. The density of the composites was $2.47 \mathrm{~g} / \mathrm{cm}^{3}$ when no nanorods were formed. The figures were $2.57 \mathrm{~g} / \mathrm{cm}^{3}$ and $2.65 \mathrm{~g} / \mathrm{cm}^{3}$ when pyrolytic carbon (PyC)-coated nanorods were formed and when typical nanorods were formed, respectively. When SiC nanorods were formed the flexural strength of the composites was 412-432 $\mathrm{MPa}$, and the fracture toughness was 13.79-14.94 $\mathrm{MPa} \cdot \mathrm{m}^{1 / 2}$. These figures were $30 \%$ and $25 \%$ higher than the flexural strength and fracture toughness of the composites without any $\mathrm{SiC}$ nanorods formed, respectively, when all other conditions were the same. In the present study, no reinforcing effect was observed by SiC nanorods coated with PyC. Further research is needed to clarify whether such an effect exists in practice. When $\mathrm{SiC}$ nanorods were formed, the room temperature thermal conductivity of the composites was $11.51 \sim 11.89 \mathrm{~W} / \mathrm{m} \cdot \mathrm{K}$, and it increased up to $25 \%$ compared to the composite prepared without $\mathrm{SiC}$ nanorod growth under the same conditions. The specific heat of the composites was not significantly affected by the manufacturing conditions applied, while the thermal conductivity was considered to be affected by the effects of nanorod formation, which increased the density, reduced larger pores into smaller ones, and improved the microstructural uniformity.

\section{Acknowledgments}

This work was supported by a National Research Foundation of Korea (NRF) grant funded by the Korean Government (MSIT) (No. 2017M2A8A401742).

\section{REFERENCES}

1. R. Naslain, "Design, Preparation and Properties of Non- 
Oxide CMCs for Application in Engines and Nuclear Reactors: An Overview," Compos. Sci. Technol., 64 [2] 155-70 (2004).

2. P. Spriet, "CMC Applications to Gas Turbines," pp. 593608 in Ceramic Matrix Composites, Materials, Modeling And Technology Ch. 21, Ed. by N. P. Bansal and J. Lamon, John Wiley \& Sons, Inc., USA, 2015.

3. C. Sauder, "Ceramic Matrix Composites: Nuclear Applications," pp. 609-46 in Ceramic Matrix Composites, Materials, Modeling And Technology, Ch. 22, Ed. by Narottam P. Bansal and Jacques Lamon, John Wiley \& Sons, Inc., USA, 2015.

4. J. Y. Park, " $\mathrm{SiC}_{\mathrm{f}} / \mathrm{SiC}$ Composites as Core Materials for Generation IV Nuclear Reactors," pp. 441-70 in Structural Materials for Generation IV Nuclear Reactors, Ch 12, Ed. by Y. Pascal, Woodhead Publishing, USA, 2017.

5. A. G. Evans and F. W. Zok, "The Physics and Mechanics of Fibre-Reinforced Brittle Matrix Composites," J. Mater. Sci., 29 [15] 3857-96 (1994).

6. V. Kostopoulos and Y. Z. Pappas, "Toughening Mechanisms in Long Fiber Ceramic Matrix Composites," pp. 120 in Comprehensive Composite Materials, Ch. 4.05, Ed. by A. Kelly and C. Zweben, Elsevier Science, 2000.

7. T. M. Besmann, B. W. Sheldon, R. A. Lowden, and D. P. Stinton, "Vapor-Phase Fabrication and Properties of Continuous-Filament Ceramic Composites," Science, 253 [5024] 1104-9 (1991).

8. R. Naslain, R. Pailler, S. Jacques, G. Vignoles, and F. Langlais, "CVI: A Versatile CMC-Processing Technique Revisited," pp. 2-14 in High Temperature Ceramic Materials and Composites, Ed. by W. Krenkel and J. Lamon, AVISO Verlagsgesellschaft mbH, D-10117 Berlin, 2010.

9. G. S. Corman and K. L. Luthra, "Melt Infiltrated Ceramic Composites $\left(\right.$ HIPERCOMP $^{\circledR}$ ) for Gas Turbine Engine Applications," DOE/CE/41000-3, 2006.

10. M. Takeda, Y. Kagawa, S. Mitsuno, Y. Imai, and H. Ichikawa, "Strength of a Hi-Nicalon ${ }^{\mathrm{TM}}$ /Silicon-CarbideMatrix Composite Fabricated by the Multiple Polymer Infiltration-Pyrolysis Process," J. Am. Ceram. Soc., 82 [6] 1579-81 (1999).

11. S. Dong, Y. Katoh, and A. Kohyama, "Preparation of SiC/ SiC Composites by Hot Pressing, Using Tyranno-SA Fiber as Reinforcement," J. Am. Ceram. Soc., 86 [1] 26-32 (2003).

12. K. Shimoda, M. Eto, and J. K. Lee, J. S. Park, T. Hinoki, and A. Kohyama, "Influence of Surface Micro Chemistry of SiC Nano-Powder on the Sinterability of NITE-SiC," pp. 101-6 in Proc. of HTCMC-5, Ed. by M. Singh, R. J. Kerans, E. Lara-Curzio and R. Naslain, Am. Ceram. Soc., USA, (2004)

13. J. Y. Park, M. H. Jeong, and W.-J. Kim, "Characterization of Slurry Infiltrated $\mathrm{SiC}_{\mathrm{f}} / \mathrm{SiC}$ Prepared by Electrophoretic Deposition," J. Nucl. Mater., 442 [1-3] S390-S393 (2013).

14. C. A. Nannetti, A. Ortona, D. A. de Pinto, and B. Riccardi, "Manufacturing SiC-Fiber-Reinforced SiC Matrix Composites by Improved CVI/Slurry Infiltration/Polymer
Impregnation and Pyrolysis,” J. Am. Ceram. Soc., 87 [7] 1205-9 (2004).

15. M. Kotani, A. Kohyama, and Y. Katoh, "Development of SiC/SiC Composites by PIP in Combination with RS," $J$. Nucl. Mater., 289 [1-2] 37-41 (2001).

16. J. Y. Park, H. S. Hwang, W. J. Kim, J. I. Kim, J. Y. Son, B. J. Oh, and D. J. Choi, "Fabrication and Characterization of $\mathrm{SiC}_{\mathrm{f}} / \mathrm{SiC}$ Composite by CVI Using the Whiskering Process," J. Nucl. Mater., 307-311 1227-31 (2002).

17. S. M. Kang, J. Y. Park, W.-J. Kim, S. G. Yoon, and W. S. Ryu, "Densification of $\mathrm{SiC}_{\mathrm{f}} / \mathrm{SiC}$ Composite by the Multistep of Whisker Growing and Matrix Filling," J. Nucl. Mater., 329-333 530-33 (2004).

18. W. Yang, H. Araki, A. Kohyama, Q. Yang, Y. Xu, and T. Noda, "The Effect of SiC Nanowires on the Flexural Properties of CVI-SiC/SiC Composites," J. Nucl. Mater., 367370 708-12 (2007).

19. J. Y. Park, S. M. Kang, W.-J. Kim, and W. S. Ryu, "Characterization of the $\mathrm{SiC}_{\mathrm{f}} / \mathrm{SiC}$ Composite Fabricated by the Whisker Growing Assisted CVI Process," Key Eng. Mater., 287 200-5 (2005).

20. Y. Ryu, Y. Tak, and K. Yong, "Direct Growth of CoreShell $\mathrm{SiC}-\mathrm{SiO}_{2}$ Nanowires and Field Emission Characteristics," Nanotechnology, 16 [7] S370-74 (2005).

21. P. Hu, S. Dong, X. Zhang, K. Gui, G. Chen, and Z. Hu, "Synthesis and Characterization of Ultralong SiC Nanowires with Unique Optical Properties, Excellent Thermal Stability and Flexible Nanomechanical Properties," Sci. Rep., 73011 (2017).

22. W.-S. Seo and K. Koumoto, "Stacking Faults in $\beta$-SiC Formed during Carbothermal Reduction of $\mathrm{SiO}_{2}$," J. Am. Ceram. Soc., 79 [7] 1777-82 (1996).

23. H.-J. Choi and J.-G. Lee, "Stacking Faults in Silicon Carbide Whiskers," Ceram. Int., 26 [1] 7-12 (2000).

24. W.-J. Kim, S. M. Kang, C. H. Jung, J. Y. Park, and W.-S. Ryu, "Growth of SiC Nanowires within Stacked SiC Fiber Fabrics by a Non-Catalytic Chemical Vapor Infiltration Technique," J. Cryst. Growth, 300 [2] 503-8 (2007).

25. J. Y. Park, S. M. Kang, and W.-J. Kim, "Development of $\mathrm{SiC}_{\mathrm{f}} / \mathrm{SiC}$ Composite by CVI with Whisker," pp. 85-91 in High Temperature Ceramic Materials and Composites, Ed. by Walter Krenkel and Jacques Lamon, AVISO Verlagsgesellschaft mbH, D-10117 Berlin, 2010.

26. G. E. Youngblood, D. .J. Senor, and R. H. Jones, Witold Kowbel, "Optimizing the Transverse Thermal Conductivity of $2 \mathrm{D}-\mathrm{SiC}_{\mathrm{f}} / \mathrm{SiC}$ Composites, II. Experimental," J. Nucl. Mater., 307-311 1120-25 (2002).

27. A. A. Balandin, "Thermal Properties of Graphene and Nanostructured Carbon Materials," Nat. Mater., 10569 81 (2011).

28. H. Tawll, Larry D. Bentsen, S. Baskaran, and D. P. H. Hasselman, "Thermal Diffusivity of Chemically Vapour Deposited Silicon Carbide Reinforced with Silicon Carbide or Carbon Fibres,” J. Mater. Sci., 20 [9] 3201-12 (1985). 